\title{
Stages of Concern in Integrating E-Learning in Discovery Schools
}

\author{
Khader AL-Rawajfih \\ School of Educational Studies, Universiti Sains Malaysia, Malaysia \\ Tel: 60-1-7468-5690 E-mail: khader_k_alrawajfih@yahoo.com \\ Soon Fook Fong (Corresponding author) \\ School of Educational Studies, Universiti Sains Malaysia, Malaysia \\ Tel: 60-1-2525-4955 E-mail: sffong05@gmail.com \\ Sharifah Norhaidah Syed Idros \\ School of Educational Studies, Universiti Sains Malaysia, Malaysia \\ Tel: 604-04-658-5414 E-mail: snsi@usm.my
}

\begin{abstract}
This study examines teachers' stages of concerns in Jordan Discovery schools on the integration of e-learning into their teaching. The moderator variables identified were gender and teaching experiences. A total of 350 teachers were randomly stratified from all secondary Discovery schools in the four districts (strata) of the capital, Amman. The findings of this study indicated that overall, Discovery school teachers are dominantly at the stage of 'personal' on the different stages of concerns. Male and female teachers do not show any difference in any of these categories but taken from the perspective of teaching experiences, only teachers in the 1-5 years were placed at the stage of 'collaboration' while the rest were at the 'personal' on the different stages of concerns. It was found that teachers' stage of management, stage of informational and stage of consequence contribute significantly on the variance of the integration of e-Learning.
\end{abstract}

Keywords: Stages of Concern, E-learning, Discovery schools

\section{Introduction}

The evolving industrial-based society into the knowledge-based society has made a big change in the social environment, at the same time, increasing the value of knowledge and together with it, we witness the rising volume of information. The changes in the broader society have made its impacts upon the educational sector as well.

By reason of these rapid changes taking place, there have been extensive changes on educational practices worldwide (Braathen \& Robles, 2000; Brown, 2000), and due to this information revolution; the educational practices have changed in new and unexpected ways. It is expected that learning will be more relevant with the emergence of information communication technologies (ICT) in the field of education not only for students but also for teachers as well. The presence of some technologies inside the classrooms brought to light what is called e-Learning. Spender (2001) ensures that e-Learning is the next generation in learning.

Different terms are usually used for this type of learning such as (e-Learning) which is considered the most used in the area of teaching and learning electronically, other terms also used are online learning, electronic education, virtual learning, and web-based learning. However, e-Learning is considered a broader concept than the concept of online learning. It is in which a wide set of applications and processes are flexibly using available electronic media to deliver vocational education and training (Davies, 1998).

In the last three decades, there has been a wide research on a main area, which are teachers' concerns. This domain is highlighted in part regarding the influence of teachers' attitude towards changes demanded by the reforms in teaching processes brought up from an innovation and its attempt to implement it (Piggie \& Marso, 1997). 
In this study we shall explore the levels of e-Learning integration in Jordanian schools for informing a professional development program to make certain that the integration effort is optimized, effective and sustainable. By this is meant, that the individual needs, concerns and how they develop as they learn about the innovation will be studied to be used by the relevant parties to set up a strong mentoring program so that Jordan can enhance its e-Learning culture.

\section{Previous Research}

Loucks-Horsley (1996) stated that the Concerns-Based Adoption Model (CBAM) is a framework which has major results for professional development in making changes in organizations and in providing support for the various needs of individuals involved in the change. In change efforts, the Concerns-Based Adoption Model (CBAM) would be an appropriate diagnostic and supportive tool in making effective change. Hord et al. (1987) reported that the CBAM can identify the special needs of individual adopters and can provide vital support through appropriate actions. Educational systems are considered organizations, which are affected by any change of an innovation. Consequently, it is important to research the whole educational organization before implementing any innovation taking under consideration that huge organizations change slowly.

More recently, a study used the Stages of Concern Questionnaire (SoCQ) to examine a project applied in North Carolina, in an attempt to implement a new algebra curriculum for all students. The authors found an important difference between initial concerns and concerns after a year of implementation for the awareness, information, and refocusing stages. As such, concerns decreased for the first two stages and increased for the third stage (Crawford, Chamblee \& Rowlett, 1998). In addition, low concerns were results of management and awareness stages. Female teachers scored high concern about management, while males scored high refocusing concern.

Al-Shammari (2000) suggested further research of validation of the (SoCQ) as a future research in Arabic Cultures (Alias \& Zainuddin, 2005). In Kuwait, a study by Al-Shammari (2000) used the Stages of Concern Questionnaire (SoCQ) as a survey on 248 teachers and found four high concerns related to collaboration, personal, refocusing, and informational stages among teachers, after the implementation of the information Technology curriculum. From a total of 126 responses, Alfieri (1998) found that self-concerns (Stages 0, 1, and 2) were relatively high and close to each other, the task concern (Stage 3) was much lower, and the impact concerns (Stages 4, 5, and 6) were even lower. Moreover, in a study to determine the Stages of Concern of North Carolina public school teachers related to $4 / 4$ block scheduling (Williams, 2001) indicated that teachers' showed concerns regarding the success of students in the classroom and the impact of $4 / 4$ block scheduling on their students. The peak stage was in the consequence stage, followed by the collaboration. However, informational concerns were the concerns of teachers with less experience more than their peers with more teaching experience.

According to Schoep's (2004), his results of the stages of concern of 69 faculty members revealed that 46 $(66.7 \%)$ of the faculty were at the self stage, $17(24.6 \%)$ at the impact stage, and finally, $6(8.7 \%)$ were at the management stage. Petherbridge (2007) found the highest concerns of faculty members were unrelated, self, and task concerns, with a slight tailing-up of impact-refocusing concerns.

In 1989 Cicchelli and Baecher found in their survey on 78 teachers in a large metropolitan city that most of the teachers have highest scores in the lower stages of concerns (Awareness, Informational, and Personal) regarding computer usage. Cicchelli and Baecher stated that teachers' concerns are on how microcomputers will affect them personally. Accordingly, teachers' concerns differ and depend on their experience about an innovation. Hope (1997) concluded that teachers' concerns about adopting microcomputers in classroom changes and develops from self concerns to impact concerns after providing teachers training courses, releasing time, modeling and technical support.

Dooley, Metcalf and Martinez (1999) conducted a study to determine a professional development programs' role in the adoption of technology. They established the percentage of teachers at different stages of concern and at different levels of technology use. Accordingly, results show that high level technology users had higher order (impact and task) concerns, and low technology users had lower order (self) concerns, and medium users had a mixture of concerns. Although the increasing amount of technology in schools, still stages of concerns related to using technology is low. In Newhouse (2001b) study, shows that 50\% of 40 teachers participated in a four year portable computer program, mostly rated at the self concern level. However, in his discussion of findings Vaughan (2002) showed that the teachers' concern about technology was stage 4, which is (Consequence). A study on 16 elementary teachers concerns related to the usage of technology showed results that about $57 \%$ of teachers are at the impact level.

In (2002) a study by Rakes and Casey concentrated on the second highest concern and the lowest concern on (659) teachers. Their findings show that teachers mostly had stage 2 (personal concerns), and the lowest findings 
were on the intensive technology integration program. In his study (2001a) Newhouse found that $53 \%$ of the teachers still have an Awareness (Stage 0) of a portable computer program at a middle school after 3 years of the program. In examining the acceptance o teachers towards the technology education curriculum, in their study Rogers and Mahler (1994) concluded that only 19 out of 80 teachers' concerns intensity were in the task and impact concerns (management, consequence, collaboration, and refocusing). And the remaining teachers had not yet accepted the innovation due to their concerns, which are still in the early stages of self concerns (awareness, informational, and personal).

To evaluate teachers' concerns towards internet integration a study conducted by Wells and Anderson (1995) at West Virginia University show that teachers' internal concerns (awareness, informational, personal, and management) decrease, and external concerns (consequence, collaboration, and focusing) increase.

\subsection{Relationship between Concerns and e-Learning Integration}

"The composite representation of the feelings, preoccupation, thought, and consideration given to a particular issue or task is called concern" (Hall \& Hord, 2001, pp. 61). The Concerns Based Adoption Model (CBAM) is a framework and set of tools for understanding and managing change in people, created through a decade of research and development (Hall \& Hord, 1987), CBAM has been in use for more than 25 years now (Horsley \& Loucks-Horsley, 1998). It is to be known that concerns of teachers regarding innovations are very important for curriculum adoption and implementation.

Various researches conducted on teachers and pre-service teachers studied the relationship of reactions to technological innovations in education, such as Hinch (2000). Teachers' personal concerns must be addressed first, when studying the teachers' concerns towards the application and use of e-Learning. Concerns about an innovation are developmental in their nature. Earlier concerns are considered lower in intensity and should be resolved before the increase in intensity of later concerns. If early concerns remain intense towards e-Learning, teachers may stop using it; thus the first step is to reduce the intensity of these concerns. Accordingly, concerns about an innovation develop toward the later stages with time, successful experience, and the acquisition of new knowledge and skill. In measuring the progress of the adoption of the innovation, CBAM and the SoCQ were used (Horsley \& Loucks-Horsley, 1998). For an effective technology adoption, faculty's different stages of concern should be acknowledged and appropriate support should be provided.

\section{Hypotheses}

This study is designed specifically to answer the above research questions, and is interpreted into the following hypotheses for a statistical purpose:

For studying the superiority of comprehensive income to net income for firm performance, we test the following hypotheses:

$\mathbf{H}_{01}$ : There is no significant contribution of self efficacy, perception on the principal's support and seven stages of concern towards the variance of integration of e-learning among teachers in Jordanian discovery schools.

$\mathbf{H}_{\mathbf{0 2}}$ : There is no significant contribution of self efficacy, perception on the principal's support and seven stages of concern towards the variance of integration of e-learning among teachers in Jordanian discovery schools, after controlling for the influence of teacher's gender and teaching experiences.

\section{Research Method}

This research looks into stages of concerns (awareness, informational, personal, management, consequence, collaboration and refocusing) based on the Concerns-based Adoption Model (CBAM) of secondary teachers in the Jordanian Discovery schools regarding the integration of e-Learning in teaching and learning. In the quantitative methods one set of questionnaire will be used in this study.

The questionnaire measures the independent variable, the peak or the most intense stage of concern and contains (35) items these consist of seven stages which are (awareness, informational, personal, management, consequence, collaboration and refocusing).

The qualitative techniques are concerned with the phenomena of research participants. It helps explain this phenomenon with a focus on the perspectives of research individuals mostly affected under the study.

The target population for this study will be Jordanian teachers in the first, second, third and fourth districts of 100 secondary Discovery schools in Amman. These schools are chosen specifically due to the government's interest in experimenting integration e-Learning and spreading this innovation over 100 Discovery schools as a test bed to ensure an effective deployment of the ICT solutions at the Ministry of Education's Schools through the Discovery School Track. Six e-curricula (Math, Science, Arabic, ICT, English as a Foreign Language and 
Civics) were developed and deployed, in different phases, at the Discovery schools. The schools are being supported with infrastructure and devices to ensure success in implementing the integration of e-Learning in these schools.

The researcher chose to focus on these four districts because they represent the urban side of the capital in which the e-Learning infrastructure has been installed more rapidly than other parts of Jordan. Also, these four districts are in location to the researcher in terms of access and delivery of the survey. (Table 1) provides a summary of the numbers of Discovery schools and teachers in the four districts of Amman.

\section{Hypothesis Testing}

The most dominant concern stage among teachers towards e-Learning integration in Jordanian discovery schools is personal with mean score $(M=5.40)$ and standard deviation (S.D. $=0.657)$ (Table 2). The second and the third most dominant concern stage are collaboration with mean score $(\mathrm{M}=5.38)$ and standard deviation (S.D. $=0.778)$ and informational with mean score $(\mathrm{M}=4.62)$ and standard deviation (S.D. $=0.864)$. The least dominant concern stage is management with a mean score $(\mathrm{M}=3.29$, and standard deviation (S.D. $=1.073)$. Subsequently, further investigation is made by analyzing the most dominant concern stage based on gender and teaching experiences.

The most dominant concern stage among male teachers towards e-Learning integration in Jordanian discovery schools is personal with mean score $(\mathrm{M}=5.33)$ and standard deviation (S.D. $=0.606)$ (Table 3$)$. The second and the third most dominant concern stage are collaboration with mean score $(\mathrm{M}=5.32)$ and standard deviation (S.D. $=0.757)$ and informational with mean score $(\mathrm{M}=4.37)$ and standard deviation (S.D. $=0.873)$. The least dominant concern stage is management with mean score $(\mathrm{M}=3.03)$ and standard deviation (S.D. $=0.926)$.

The most dominant concern stage among female teachers towards e-Learning integration in Jordanian discovery schools is personal with mean score $(M=5.44)$ and standard deviation (S.D. $=0.681)$ (Table 4). The second and the third most dominant concern stage are collaboration with mean score $(\mathrm{M}=5.41)$ and standard deviation (S.D. $=0.789)$ and informational with mean score $(\mathrm{M}=4.75)$ and standard deviation (S.D. $=0.831)$. The least dominant concern stage is management with mean score $(\mathrm{M}=3.42)$ and standard deviation (S.D. $=1.123$ ).

The most dominant concern stage among teachers which have 1 to 5 years of teaching experiences towards e-Learning integration in Jordanian discovery schools is collaboration with mean score $(M=5.61)$ and standard deviation (S.D. $=0.700)($ Table 5). The second and the third most dominant concern stage are personal with mean score $(M=5.49)$ and standard deviation (S.D. $=0.575)$ and informational with mean score $(M=4.96)$ and standard deviation $($ S.D. $=0.859)$. The least dominant concern stage is management with mean score $(\mathrm{M}=4.19)$ and standard deviation (S.D. $=1.404)$.

The most dominant concern stage among teachers which have 6 to 10 years of teaching experiences towards e-Learning integration in Jordanian discovery schools is personal with mean score $(\mathrm{M}=5.35)$ and standard deviation (S.D. $=0.716)($ Table 6$)$. The second and the third most dominant concern stage are collaboration with mean score $(M=5.33)$ and standard deviation (S.D. $=0.812)$ and informational with mean score $(M=4.59)$ and standard deviation (S.D. $=0.891)$. The least dominant concern stage is management with mean score $(\mathrm{M}=3.04)$ and standard deviation (S.D. $=0.753$ ).

The most dominant concern stage among teachers which have 11 to 15 years of teaching experiences towards e-Learning integration in Jordanian discovery schools is personal with mean score $(M=5.37)$ and standard deviation (S.D. $=0.618)$ (Table 7). The second and the third most dominant concern stage are collaboration with mean score $(M=5.24)$ and standard deviation (S.D. $=0.711)$ and informational with mean score $(M=4.45)$ and standard deviation (S.D. $=0.678)$. The least dominant concern stage is management with mean score $(\mathrm{M}=2.85)$ and standard deviation (S.D. $=0.600$ ).

The most dominant concern stage among teachers which have 16 to 20 years of teaching experiences towards e-Learning integration in Jordanian discovery schools is personal with mean score $(M=5.41)$ and standard deviation (S.D. $=0.667)($ Table 8). The second and the third most dominant concern stage are collaboration with mean score $(M=5.26)$ and standard deviation (S.D. $=0.823)$ and informational with mean score $(M=4.31)$ and standard deviation (S.D. $=0.829)$. The least dominant concern stage is management with mean score $(\mathrm{M}=2.96)$ and standard deviation (S.D. $=0.655)$.

\section{Discussion}

The results of descriptive statistical analysis showed that the most dominant concern stage amongst teachers towards e-learning integration in Jordanian discovery schools is personal $(\mathrm{M}=5.40, \mathrm{~S} . \mathrm{D} .=0.657)$. The results also revealed that the personal was the most dominant concern stage towards e-learning integration in Jordanian 
discovery schools for male $(\mathrm{M}=5.33$, S.D. $=0.606)$ and female $(\mathrm{M}=5.44$, S.D. $=0.681)$ teachers. Based on years of teaching experiences, it was found the personal was the most dominant stage for teachers who have 6 to 10 years of teaching experiences $(\mathrm{M}=5.35$, S.D. $=0.716), 11$ to 15 years of teaching experiences $(\mathrm{M}=5.37$, S.D. $=0.618)$ and 16 to 20 years of teaching experiences $(M=5.41$, S.D. $=0.667)$. However, an inconsistent result was found for teachers who have 1 to five years of teaching experiences as the collaboration stage $(\mathrm{M}=5.61, \mathrm{~S} . \mathrm{D} .=0.700)$ was recognized as the most dominant stage of concern towards integration of e-learning.

The level of stage of concern towards integration of e-learning can be understood by referring to the Concern Based Adoption Model (CBAM) which showed how an innovation moves through sequentially (Ensminger et al., 2004). The model describes how individuals develop as they learn about an innovation and the stage of the process (Horsley \& Loucks-Horsley, 1998). This current research found that the most dominant stages of concerns among teachers in Jordanian Discovery schools generally are in the personal stage. According to CBAM (Hall et. al, 1998), the personal stage refers to the concerns about the impact of innovation on teachers. At this stage, teachers will build basic concerns on how to use of the innovation will affect them in person. This stage is considered as an early stage as it clustered together with other two earlier stages which are awareness and information (Fuller, 1969). According to Fuller (1969), the cluster of these three stages lay on the self-concern phase which is considered as early stages of integrating e-learning through the teaching and learning process and there is still resistance towards change in the learning process.

The findings of the study are consistent with Schoep (2004) who found that majority of the faculty members in his study still at the self-concern phase. Cicchelli and Baecher (1989) found in their survey on teachers in a large metropolitan city that most teachers have highest scores in the lower stages of concern regarding computer usage. They reported that teachers' concerns are on how microcomputers will affect them personally. Newhouse (2001b) found that most of the sample in the study who participated in a four-year portable computer program rated at self-concerns level.

Further analysis by years of teaching experiences indicated that teachers who have 6 to 10 years, 11 to 15 years and 16 to 20 years of teaching experiences remained at the personal stage level. On the other hand, teachers who have 1 to 5 years of teaching experiences are in more advanced level of the concern which are in the collaborative stage. According to CBAM (Hall et. al, 1998), collaborative stage refers to working with others to implement the innovation. Here teachers relate what they are doing to what colleagues do. The collaborative stage is considered as the second highest stage among all the stages of concern. It can be inferred that groups of teachers who have 1 to 5 years of teaching experiences in Jordanian school have higher concern on the integration of e-learning compared to other group of teacher who have more years of teaching experiences.

Probably, the findings of the study can be connected with findings of the self-efficacy on the integration of e-learning among teachers who have different years of teaching experiences. The connection lied on the similarity of the higher level of the self efficacy and the stage of concern among teachers who have 1 to 5 years of teaching experiences compared to group of teachers who have more years of teaching experiences (6 to 10 years, 11 to 15 years and 16 to 20 years). The finding suggests that experienced teachers or teachers with long experience in the field of teaching are lagging behind younger teachers in terms of e-learning integration. A study by Fletcher and Deeds (1994) concluded that teachers with relatively more years of service or more needed training that was different from teachers who have relatively less years of service. This was because teachers with relatively less years of service had some exposure to the use of computers for teaching training while in college. Todd (1993) in his study found that the most users who used technology for teaching purposes (instructional users) had higher levels of impact concerns than those who used computers of their personal purposes only (non-instructional users). Thus, it can be assumed that teachers who have 1 to 5 years of teaching experiences have had more exposures on the usage of the computers during teaching training which probably contributed to the higher concern on the integration of e-learning. As technology become more advanced year by year, it is speculated that teachers who have 1 to 5 years of teaching experiences are exposed to more advanced technology which are integrated into the teaching and learning process. Dolley, Metcalf and Martinez (1999) found in their study that more advanced technology users had higher stages of concern, and less advanced technology users had lower stages of concern. Hall and Hord (1997) stated that teachers with no use of an innovation have little or no knowledge about it which in turn exhibit little concern about learning more. However, the experienced user is less egocentric on persons and on the goal of collaboration for a more comprehensive delivery of the innovation (Hall \& Hord, 1987; Bellah \& Dyer, 2007).

The results of standard multiple regression tests showed that teachers' perception towards principals' support, and three stages of concern which are management, informational and consequence contribute significantly on the integration of e-learning. It is noted that the model explains 11.0 percent of the variance in the integration of 
e-learning. In order to control the influence of teacher's gender and years of teaching experiences in analyzing the best predictor variables on the integration of e-learning, the standard multiple regression test was replaced by the hierarchal multiple regression test. The result of hierarchal multiple regression test confirmed the results of standard multiple regression test which found that teachers' perception towards principals' support and three stages of concern which are management, informational and consequence contributed significantly on the integration of e-learning. It was noted that the model explained an additional $10.9 \%$ of the variance in the integration of e-learning, after controlling for teachers' gender and teaching experiences.

Without concerning the negative or positive values of the Beta coefficient $(\beta)$, it can be interpreted that the second, third and fourth strongest unique contribution on the integration of e-learning were the three stages of concerns which are management $(\beta=-0.189, \mathrm{t}=-2.492, \mathrm{p}<0.05)$, consequence $(\beta=0.170, \mathrm{t}=2.407, \mathrm{p}<0.05)$ and informational $(\beta=-0.160, t=-2.397, p<0.05)$. Therefore, when the score of the stage of management increased by 1 unit, therefore, the integration of e-learning decreased by $18.9 \%$. Next, when the score of the stage of consequence increased by 1 unit, thus, the integration of e-learning increased by $17.0 \%$. Lastly, when the score of stage of informational increased by 1 unit, thus, the integration of e-learning decreased by $16.0 \%$.

The findings showed that the stage of management and informational contribute negatively to the integration of e-learning among Jordanian discovery school teachers. According to CBAM, teachers who are in stage of management are more focusing on different ways to manage and control this innovation effectively over the organization and details of implementation and the overcoming difficulties (Hall et. al, 1998). Whereas CBAM also theorize that teachers in the stage of informational are more focused on the teachers' willingness to learn more about the innovation (Hall et. al, 1998). Both characteristics showed a similarity where teachers are more focused on themselves for the preparation purposes in terms of barriers, management, knowledge and skills for the integration of e-learning. Thus, it can be argued that the more they think how prepared they are to integrate e-learning, consequently, the less tendency for them to implement frequently the integration of e-learning.

On the other hand, the findings of current study showed that teachers' stage of consequence contributes positively to the integration of e-learning among Jordanian discovery school teachers. According to CBAM (Hall et al., 1998), teachers in stage of consequences focus more on how the innovation affects learning. This stage is less egocentric as it more focuses on the external factor such as the outcomes of the students. Hall and Hard (1987) and Bellah and Dyer (2007) found that experience user is less egocentric in his or her concerns, and they focus on the impact of the innovation on persons. Based on CBAM, if these outcomes or impacts are positive, teachers are likely to continue work for the implementation (Hall et al., 1998). This group of teachers is belonged to the stage of consequences whereby they have the tendency to implement frequently the integration of e-learning if they observe the positive outcomes on the students' learning.

This study showed that the level of the integration of e-learning among teachers in Jordanian discovery school students is at the moderate level.

Based on the seven stages of concern using CBAM, most of the teachers are still at the early stages of concern on the integration of e-learning except teachers who have 1 to 5 years of teaching experiences. It is speculated that the exposure of advance technology during the training years by teachers who have 1 to 5 years of teaching experiences possibly be one of the factors which positioned them in the higher level of the concern,. Thus, it is suggested that teachers who have more than 6 years of teaching experiences should be retrained to expose them with the most current technology used in the teaching and learning process. This study found that three stages of concern contribute to implementation of e-learning among teachers in Jordanian secondary discovery schools management, informational and consequences.

\section{References}

Alfieri, P. A. (1998). Stages of concern of defense systems management college faculty bout technology-based education and training. PhD Dissertation. The Faculty of the Virginia Polytechnic Institute and State University.

Alias, N. A., \& Zainuddin, A. M. (2005). Innovation for better teaching and learning: Adopting the learning management system. Malaysian Online Journal of Instructional Technology, 2(2), p.27-40.

Alshammari, B.S. (2000). The development stages of concern of teachers toward the implementation of the information technology curriculum in Kuwait. PhD Dissertation (Unpublished). University of North Texas.

Bellah, K. A., \& Dyer, J. E. (2007). Elementary Teachers' Attitudes and Stages of Concern About an Agricultural Literacy Curriculum. Proceedings of the 2007 AAAE Research Conference, 34, p.66-81.

Braathen, S., \& Robles, M. (2000). The importance of assessment in business education”, In J. Rucker \& R. J. Schoenrock (Eds.), National Business Education Yearbook, Reston, Virginia: National Business Education 
Association, 32, p.11-24.

Brown, B. J. (2000). New assessment strategies to improve business teacher preparation. In J. Rucker \& R. J. Schoenrock (Eds.), National Business Education Yearbook, Reston, Virginia: National Business Education Association, 38, p.143-157.

Cicchelli, T., \& Beacher, R. (1989). Microcomputers in the classroom: Focusing on teacher concerns. Educational Research Quarterly, 13(1), p.37-46.

Crawford, A. R., Chamblee, G. E., \& Rowlett, R. J. (1998). Assessing concerns of algebra teachers during a curriculum reform: A constructive approach. Journal of In-service Education, 24, p.317-327.

Davies, D. (1998). The virtual university: A learning university. The Journal of Workplace Learning, 10(4), p.175-213.

Dooley, L. M., Metcalf, T., \& Martinez, A. (1999). A study of the adoption of computer technology by teachers. Educational Technology \& Society, 2(4), p.107-115.

Ensminger, D. C., Surry, D., Porter, B. E., \& Wright, D. (2004). Factors Contributing to the Successful Implementation of Technology Innovations. Educational Technology \& Society, 7 (3), p.61-72.

Fletcher, W. E., \& Deeds, J. P. (1994). Computer anxiety and other factors preventing computer use among United States secondary agricultural educators. Journal of Agricultural Education, 35(2), p.16-21.

Fuller, F. F. (1969). Concerns of teachers: A developmental conceptualization. American Educational Research Journal, 6, p.207-226.

Hall, G.E., \& Hord, S. M. (2001). Implementing Change: Patterns, Principal and Potholes. Allyn and Bacon: Needham Heights.

Hall, G.E., \& Hord, S.M. (1987). Change in schools: Facilitating the process. Albany, NY: State University of New York Press.

Hinch, S. W. (2000). Stages of concern and frequency of use of computer-based resources by middle school social studies teachers. Dissertation Abstracts International, 61(12), p.46-59.

Hope, W. C. (1997). Resolving teachers' concerns about microcomputer technology. Computers in the Schools, 13(3/4). 147-160.

Horsley, D.L. \& Loucks-Horsley, S.. (1998). CBAM brings order to the tornado of change. Journal of Staff Development, 19(4), p.17-20.

Jordanian Ministry of Education, 2009. Amman, Jordan.

Loucks-Horsley, S. (1996). The concerns-based adoption model (CBAM): A model for change in individuals. In: National Standards \& the Science Curriculum. Dubuque, Iowa: Kendall/Hunt Publishing Co.

Mettam, G. R., \& Adams, L. B. (1994). How to prepare an electronic version of your article. In B. S. Jones, \& R. Z. Smith (Eds.), Introduction to the electronic age. New York: E-Publishing Inc. pp. 281-304

Newhouse, P. (2001a). Applying the Concerns-Based Adoption Model to research on computers in classrooms. Journal of Research on Technology in Education, 33(5).

Newhouse, P. (2001b). A follow-up study of students using portable computers at a secondary school. British Journal of Educational Technology, 32(2), p.209-219.

Petherbridge, D. T. (2007). A concerns-based approach to the adoption of web-based learning management systems. PhD Dissertation. The Graduate Faculty of North Carolina State University. Raleigh, North Carolina.

Pigge, F. L., \& Marso, R. N. (1997). A Seven Year Longitudinal Multi-Factor Assessment of Teaching Concerns Development Through Preparation and Early Years of Teaching, Teaching and Teacher Education, 13(2), p.225-235.

Rakes, G. C., \& Casey, H. B. (2002). An analysis of teacher concerns toward instructional technology, International Journal of Educational Technology, 3(1).

Rogers, E. M. (1995). Diffusion of innovations. $4^{\text {th }}$ ed. New York: The Free Press.

Rogers, G. E., \& Mahler, M. (1994). Non-acceptance of technology education by teachers in the field. Journal of Technology Studies, 20 (1), p.15-20.

Schoep, K. W. (2004). Technology integration barriers in a technology-rich environment: A CBAM Perspective. 
Phd Thesis. The faculty of graduate studies, Calgary, Alberta.

Spender, D. (2001). E-learning: are schools prepared?. The Annual Washington Conference on e-learning in A Borderless Market, Washington, D.C. p.21-33.

Todd, N. I. (1993). Faculty concerns as gateways to teacher competency with computer technology. Paper presented at the Convention of the Association for Educational Communications and Technology, New Orleans, Louisiana (ERIC Document Reproduction Service No. ED362209).

Vaughan, W. (2002). Professional development and the adoption and implementation of new innovations: Do teacher concerns matter?. International Electronic Journal For Leadership in Learning, 6(5).

Wells, J. G., \& Anderson, D. K. (1995). Teachers' stages of concerns towards Internet integration. Research Report. (ERIC Document Service No. ED 389261)

Williams, S. A. (2001). Stages of concern of teacher in north Carolina $4 / 4$ block scheduled public schools. PhD Dissertation. the Faculty of the Virginia Polytechnic Institute and State University.

Table 1. Discovery schools and teachers in the four districts of Amman (JMOE, 2009)

\begin{tabular}{llcc}
\hline No. & District & School & Teachers \\
\hline 1. & Amman First district & 47 & 1162 \\
2. & Amman Second district & 32 & 744 \\
3. & Amman Third district & 2 & 97 \\
4. & Amman Fourth district & 19 & 386 \\
\hline & Total & 100 & 2389 \\
\hline
\end{tabular}

Table 2. The arrangement of seven stages concern based on the mean score

\begin{tabular}{lll}
\hline & Mean & Std. Deviation \\
\hline Personal & 5.40 & 0.657 \\
Collaboration & 5.38 & 0.778 \\
Informational & 4.62 & 0.864 \\
Consequence & 4.19 & 1.094 \\
Awareness & 3.76 & 0.872 \\
Refocusing & 3.59 & 1.046 \\
Management & 3.29 & 1.073 \\
\hline
\end{tabular}


Table 3. The arrangement of seven stages concern for male teachers based on the mean score

\begin{tabular}{lll}
\hline & Mean & Std. Deviation \\
\hline Personal & 5.33 & 0.606 \\
Collaboration & 5.32 & 0.757 \\
Informational & 4.37 & 0.873 \\
Consequence & 3.94 & 1.090 \\
Awareness & 3.56 & 0.872 \\
Refocusing & 3.39 & 0.913 \\
Management & 3.03 & 0.926 \\
\hline
\end{tabular}

Table 4. The arrangement of seven stages concern for female teachers based on the mean score

\begin{tabular}{lll}
\hline & Mean & Std. Deviation \\
\hline Personal & 5.44 & 0.681 \\
Collaboration & 5.41 & 0.789 \\
Informational & 4.75 & 0.831 \\
Consequence & 4.33 & 1.073 \\
Awareness & 3.86 & 0.856 \\
Refocusing & 3.70 & 1.099 \\
Management & 3.42 & 1.123 \\
\hline
\end{tabular}

Table 5. The arrangement of seven stages concern for teachers which have 1 to 5 years of teaching experiences based on the mean score

\begin{tabular}{lll}
\hline & Mean & Std. Deviation \\
\hline Collaboration & 5.61 & 0.700 \\
Personal & 5.49 & 0.575 \\
Informational & 4.96 & 0.859 \\
Consequence & 4.72 & 1.139 \\
Refocusing & 4.28 & 1.409 \\
Awareness & 4.26 & 1.097 \\
Management & 4.19 & 1.404 \\
\hline
\end{tabular}


Table 6. The arrangement of seven stages concern for teachers which have 6 to 10 years of teaching experiences based on the mean score

\begin{tabular}{lll}
\hline & Mean & Std. Deviation \\
\hline Personal & 5.35 & 0.716 \\
Collaboration & 5.33 & 0.812 \\
Informational & 4.59 & 0.891 \\
Consequence & 4.08 & 1.067 \\
Awareness & 3.58 & 0.700 \\
Refocusing & 3.41 & 0.814 \\
Management & 3.04 & 0.753 \\
\hline
\end{tabular}

Table 7. The arrangement of seven stages concern for teachers which have 11 to 15 years of teaching experiences based on the mean score

\begin{tabular}{lll}
\hline & Mean & Std. Deviation \\
\hline Personal & 5.37 & 0.618 \\
Collaboration & 5.24 & 0.711 \\
Informational & 4.45 & 0.678 \\
Consequence & 3.94 & 0.905 \\
Awareness & 3.60 & 0.726 \\
Refocusing & 3.30 & 0.733 \\
Management & 2.85 & 0.600 \\
\hline
\end{tabular}

Table 8. The arrangement of seven stages concern for teachers which have 16 to 20 years of teaching experiences based on the mean score

\begin{tabular}{lll}
\hline & Mean & Std. Deviation \\
\hline Personal & 5.41 & 0.667 \\
Collaboration & 5.26 & 0.823 \\
Informational & 4.31 & 0.829 \\
Consequence & 3.92 & 1.022 \\
Awareness & 3.56 & 0.687 \\
Refocusing & 3.25 & 0.586 \\
Management & 2.96 & 0.655 \\
\hline
\end{tabular}

